\title{
Current status on applications of conventional breeding techniques and biotechnological system in ornamentals
}

\author{
Jong Bo Kim
}

Received: 29 April 2020 / Revised: 2 May 2020 / Accepted: 2 May 2020

(C) Korean Society for Plant Biotechnology

\begin{abstract}
Flower industry is now growing due to the development of economy in many countries. Simultaneously, needs from consumers in flower market are varied widely. To satisfy the needs from consumers and deal with a variety of diseases from a lots of pathogens as well as climate change, new elite flower cultivars should be released in flower market. For this purpose, conventional and biotechnological techniques can be employed to make good cultivar. Therefore, this review describes the general overview of flower breeding techniques including cross-hybridization, mutation breeding and genetic transformation systems. Also, breeding systems for ornamentals derived from plant tissue culture such as embryo culture, in vitro fertilization, ovary/ovule culture and haploid production were reviewed. Furthermore, in this study recent development of the generation of new flower cultivars using marker-assisted breeding, plant transformation including particle bombardment and Agrobacterium tumefaciens as well as genome-editing technology were described. This review will be contributed to the development and releasement of new flower cultivars with horticulturally useful traits in the future.
\end{abstract}

Keywords Agrobacterium, Breeding, Genome-editing, Mutation, Ornamentals, Particle bombardment, Transformation

\section{Introduction}

Flower breeding

Generally, flower breeding is focused on generating as much genetic variation as possible. First, genetic variations in wild species are searched for breeding purpose. Then,

\section{J. B. Kim $(\triangle)$}

Department of Biotechnology, Research Institute for Biomedical and Health Sciences, College of Biomedical \& Health Sciences, Glocal Campus. Konkuk University, Choong-Ju, 27478, Korea e-mail: jbhee1011@kku.ac.kr a breeder would make crosses and selections. Alstroemeria species can also be doubled in terms of genomes to get larger flowers. Most of the cultivars are triploid or tetraploid. The wild species are diploid. To make crossings between species, crossing barriers are found, which are to be overcome by ovule cultures in vitro. The ovules are sectioned out of the ovaries and cultured in vitro 48 hours after pollination. Some ovules will develop seedlings and young plants. Through this method, the production of interspecific hybrids with interesting characteristics is possible. Some of these hybrids are tested in different companies' greenhouses. If the chromosomes of these interspecific hybrids are doubled, the result is a fertile plant that can be used for crossing. For instance, by crossing species $\mathrm{AA}$ and species $\mathrm{BB}$, the cross is $\mathrm{AB}$. Because the two genomes are different, this hybrid will be sterile. Only a very small percentage of unreduced gametes can be formed. The formation of unreduced gametes can thus be selected. We have found hybrids with up to $20 \%$ unreduced gametes. These factors are very interesting for crossing; they result in triploid offspring because $A B$ produces $A B$ gametes. $B y$ crossing $A B$ with species $C C$, the result is species $A B C$ in which three different species are present with their specific characteristics.

Important characteristics

Generally, breeding for ornamentals is focused on totally different characteristics compared to edible crops. The rule in ornamentals is to breed for diversity: if there is something new in an ornamental, it is good for commercialization. These features can include a new color, a mixed color pattern, double flowers, a different flower shape, large flowers or mini flowers, fragrance, variegated leaves, different plant types from cut flower plants to pot plants, etc. Other important features are more general, like the yield and quality. In cut flower breeding, quality means strong stems, a large number 
of flowers per stem, a good flower color, a long vase life, flowers with leaves along the flower stem, and good survivability within the leaves (no yellowed leaves). Quality also encompasses disease-free plant material (as the starting material) and disease-free and insect-free products on the flower market. For this reason, the cultivation of ornamentals has been supported for many years by the use of pesticides, but nowadays, because the use of pesticides is limited, other methods like breeding for resistance will become more and more important in ornamental breeding.

\section{Genetics}

Breeding for color is one of the most important goals in ornamentals. In most ornamentals, the genetics behind the flower color are unknown. Breeders cross red flowers with red to obtain red, pink with pink, white with white, etc. (in cyclamen breeding) without having knowledge about the genetics of the ornamental. Classical methods to breed for flower color are based on pigments and the knowledge of dominance, co-dominance, and recessiveness. Modern biotechnological breeding methods to obtain flower color are based on changes in the metabolic pathways behind the production of anthocyanins. Due to the molecular approach, basic knowledge of these anthocyanin pathways and the environmental influences determining the flower color is now available (Mol et al. 1995; Forkmann et al. 1995).

Two main pigment synthesis pathways are known: one based on carotenoids responsible for the color yellow and one based on anthocyanins responsible for the colors red and purple. The carotenoids are present in the chromoplasts whereas the anthocyanins are present in the cell vacuoles.

Natural genetic variation

The first task that needs to be done when breeding new species of ornamentals is to look for wild relatives to get an idea of how expansive the natural genetic variation is. For wild species with a great diversity for flower colors, plant growth and habits generally occur. In addition, plants that are resistant to pests and diseases are found in nature. To determine this natural genetic variation, one should find a plant species' place of origin. Breeding roses for cut flower production started with the cross of the European Rosa gallica with the Chinese Rosa gigantea to achieve the perpetually flowering trait found in rose varieties (continuous flowering is based on a recessive monogene). Additionally carnation species flower once a year (garden carnation varieties). Dianthus caryophyllus was crossed with Dianthus lignosus, a bushy plant that flowered in the wintertime. With this cross, the trait of continuous flowering under good conditions was added to the newly developed carnation cultivars. For example, the Alstroemeria genus originates from South America, especially Chile and Brazil. Some species are also found in Peru, Argentina, and Venezuela. Thirty-five different Chilean species were described by Bayer (1987), and there are more known throughout Brazil, although no monograph of the Brazilian species has yet been published. All these species together present the total natural diversity of the genus Alstroemeria. When combined together by crosses and genetic recombinations, a huge variation of genes can be explored for breeding purposes. When the breeder has built up a collection of wild species, the second step is to start a crossing program. Species that are closely related will cross more easily with each other than distantly related species. In all interspecific crossing programs, crossing barriers will appear sooner or later. These crossing barriers must be overcome by several different techniques depending in the place where the crossing barriers are presented.

\section{Crossing barriers and techniques to overcome}

We can distinguish crossing barriers in three different categories depending on the position in the fertilization process in which they occur:

- pre-fertilization when the pollen tubes are inhibited from germination and growth,

- no fertilization at all,

- post-fertilization after the fusion of the two gametes the zygote has been aborted.

In all categories, a number of techniques are available for overcoming these barriers. These techniques vary from easily applied techniques to very labor-heavy and time-consuming techniques. Van Tuyl and De Jeu (1997) have provided an overview about these techniques.

\section{Pre-fertilization barriers}

After the pollination of a mature (exudate-rich) stigma, the pollen will germinate, and the pollen tubes will grow into the stigma and the style, which connects the stigma to the ovary where the ovules are present. During this process, the inhibition of pollen tube growth often occurs in interspecific crossings. This inhibition is found in different locations in the style and can be complete or incomplete. Depending on the location of the inhibition, the stigma and part of the 
style can be removed, and the remaining cut style can be pollinated again. The application of this method in Alstroemeria needs the addition of an exudate on the surface of the cut style to achieve pollen germination. Alstroemeria have a hollow style channel through which only the pollen tubes grow. The pollen tubes can grow into the channel after the style is cut and still survive. Another method is style grafting in which a compatible style is grafted onto an incompatible ovary. Pollen tube growth will take place in the compatible style and will continue in the incompatible ovary. The application of this technique should be done under aseptic conditions to gain the best results. Van Tuyl et al. (1991) produced hybrids between Asiatic and Oriental lilies using the graft style technique.

\section{Post-fertilization barriers}

After fertilization, the embryo can be aborted during seed development. In most cases, this is due to a defect in the growth of the endosperm, as revealed by Busmann-Loock et al. (1992) in Lupinus sp. and by Ishizaka and Uematsu (1992) in Cyclamen. De Jeu and Garriga Calderé (1997) studied embryo abortion in the interspecific cross between Alstroemeria pelegrina x Alstroemeria aurea histologically. In this combination, the first division of the zygote after fertilization was already retarded, thus resulting in abnormal embryo growth. Due to this abnormal growth, sporophytic tissue responsible for the nutrition of the embryo started to degenerate very early, and in addition, the coenocytic endosperm did not develop further into a cellular endosperm. All these processes seemed to evolve subsequently after the first abnormal division of the zygote.

Many different embryo rescue techniques have been developed in different ornamentals depending on the moment of embryo abortion. In Alstroemeria, De Jeu and Jacobsen (1995) developed a method for ovule culture applied two days after pollination. The pollinated ovaries were surface sterilized, and the ovules were dissected out of the ovaries and cultured on a hormone-free MS medium (Murashige and Skoog 1962) with 9\% saccharose. After two months, the ovules were cultured on an MS medium supplied with only $3 \%$ sucrose in which most of the ovules germinated normally without a callus phase. This technique delivered hybrids between distantly related Alstroemeria species in a very fast and efficient way that was even faster than normal seed development and germination for compatible combinations. Delphinium interspecific hybrids were obtained directly by germinating the ovule by applying an ovule culture $20 \sim 25$ days after pollination (Honda and Tsutsui
1997). A Cyclamen ovule culture was applied 21 or 28 days after pollination depending on the ploidy level of the maternal parent for the production of interspecific hybrids between Cyclamen persicum and Cyclamen hederifolium (Ishizaka and Uematsu 1992). In this example, the ovules were cultured together with the placental tissue.

Embryo cultures are applied to many ornamentals like Lilium (Van Tuyl et al. 1991), Tulipa (Van Creij 1997), Freesia (Reiser and Ziessler 1989), Alstroemeria (Buitendijk et al. 1995), and others. In all these examples, the embryos were partly isolated from the ovules (and ovaries) just before embryo abortion occurred. In several cases, embryo culturation was performed in a liquid medium to ensure that the embryos received enough nutrition for growth. Nutrition-rich media also induce embryonal callus growth, which directly provides a multiplication system if shoots and roots are to be regenerated from the callus. Combinations of ovary, ovule, and embryo cultures were also made. The ovary can be pollinated and cultured in vitro, and afterwards the ovules or embryos are dissected out of the ovary for ovule or embryo culturing, such was applied in Lilium (Van Tuyl et al. 1991). In addition, the "ovary slicing technique" can be applied when the ovaries can be maintained for a longer period in the plant. In this method, the ovules are still in contact with placental tissue when they are cultured in vitro, which could favor the development of the embryos, as has described for Nerine, Lilium, and Tulipa species (Van Tuyl et al. 1993).

\section{In vitro fertilization of isolated ovules or egg cells}

If fertilization is not achieved in a natural way using one of the different methods described above, in vitro fertilization of isolated ovules is an option. Ovules can be pollinated directly by bringing aseptic pollen in contact with ovules in vitro. Attempts were made in Lilium (Janson et al. 1993) and in Alstroemeria, but they were not successful in all cases. The germination of pollen was poor, and the pollen tubes did not grow directly into the micropyle but instead twisted around the entrance. The in vitro fertilization techniques used for maize (Kranz and Lörz 1993) and for Nicotiana tabacum (Tian and Russell 1997) where isolated male gametes fused together with isolated egg cells are promising methods, which could be applied to more crops in the future. For this method, three basic requirements need to be fulfilled: 1) isolation of the male and female gametes, 2) microfusion of the gametes, and c) culturing of the zygote into a differentiated embryo and subsequently, into a plantlet. 


\section{Somatic hybridization}

For several crops, experiments were done to fuse protoplasts and to regenerate the fusion products for plantlets to produce somatic hybrids in cases in which pollination, fertilization, and embryo rescue techniques were not applicable. In Alstroemeria, Kim et al, (2005) demonstrated that protoplasts were isolated and regenerated into plants with a high efficiency. Nakano and Mii (1993) produced a hybrid between Dianthus chinensis and Dianthus barbatus using this method. The somatic hybrid proved to be an interspecific hybrid according to flower color, number of chromosomes, and nuclear rDNA analysis. Attempts were made to produce a frost tolerant Hibiscus using somatic hybridization to cross Hibiscus rosasinensis and Lavatera thuringiaca. However, the fusion products did not regenerate into plants (Vazquez-Thello et al. 1996).

$\mathrm{F}_{1}$-sterility and the application of unreduced gametes

After the labor-intensive production of interspecific hybrids, another barrier for introgression will appear: the sterility of the hybrid. Chromosome doubling in vitro with the use of colchicine or oryzalin (Van Tuyl et al. 1992) can solve this problem. It is also possible to select hybrids that produce a percentage of viable pollen, which are in most cases, unreduced gametes (Ramanna 1992). In a F1 progeny of sixty plants obtained after ovule culturing out of the cross between a tetraploid Alstroemeria cultivar (cv 118) and the diploid species Alstroemeria aurea, the production of viable pollen was determined by the use of lactophenol acid fuchsin as a cytoplasm coloring agent. The percentage of viable pollen of all plants varied between $0 \sim 40 \%$; most of the plants had a percentage of viable pollen of $0 \sim 5 \%$ (33 plants) whereas five plants had a percentage of viable pollen of $20 \%$ or more. This indicates that the selection for the most fertile hybrid is possible, although a large quantity of hybrids must be produced.

The use of unreduced gametes is a big opportunity to breed ornamentals because a higher ploidy level generally implies a larger flower, a thicker flower stem, more flowers per stem, etc. Unreduced gametes favor ornamentals in special traits, which are important in ornamentals. The use of unreduced gametes directly gives triploid (in the cross $2 \mathrm{X} \times \mathrm{X}$ ) and tetraploid (in the cross $2 \mathrm{X} \times 2 \mathrm{X}$ ) offspring without the use of colchicine or oryzalin. The production of triploids implies more or less sterility in the plants. In case of breeders' protection, this favors the breeder as it allows the breeder to keep the genetic plant material for their own use. In small crops in which a breeder's right is not yet accepted, this could be a breeder's goal. In rose breeding, the European roses were tetraploid, and the Chinese and Asian roses were diploid. Crosses between these were triploid and nearly sterile. In this case, roses can be multiplied in a vegetative manner so the sterility of the hybrid is not a problem, although this blocks further breeding activities.

Haploid culturing by androgenesis and gynogenesis

Especially in ornamentals propagated through vegetative propagation in which the cultivars consist of complex hybrids, mass propagation by seeds is still a demand. In vitro multiplication is labor-intensive, and the basic plants must be kept healthy. The production of hybrid seeds by inbreeding parental lines and crossing between those lines would be a good alternative. For this reason, the production of haploids started in diverse ornamentals like the Gerbera (Meynet and Sibi 1984, De Wit 1990), Lilium (Han et al. 1997), Tulipa (Van de Bulk et al. 1994), and Alstroemeria species. In Gerbera, De Wit (1990) used unpollinated ovules for the delivery of haploid callus lines, which could be regenerated into haploid plants. Han et al. (1997) succeeded in the regeneration of haploid plants from anther cultures of the Asiatic hybrid lily "Connecticut King." Van de Bulk et al. (1994) produced embryoid-like structures from microspores of Tulipa that could be regenerated into small bulbs. Anther cultures in a tetraploid cultivar of Alstroemeria resulted in a good regenerating callus line of a haploid nature. Out of this, callus plants regenerated, which flowered and showed their (di)haploid nature in the size of the flowers. In addition, the number of chromosomes in metaphase chromosome preparations proved the (di)haploid nature of the plants. Therefore, in principle, all methods applied for haploid production were possible in ornamentals, but the results were rather poor. Androgenesis or gynogenesis may also deliver a regenerating callus that can be used for other purposes. It is expected that haploid callus lines can be doubled either spontaneously or by the application of colchicine or oryzalin (Van Tuyl 1992).

Although the number of ornamental species referred to in this review is restricted, the different in vitro techniques are very important for their application in ornamental breeding both classically with the use of interspecific hybridization and molecularly with the use of gene delivery systems. For each ornamental species-specific in vitro technique that has to be developed; there are no general protocols available. Devising generally applicable protocols for ornamentals will be the challenge in ornamental breeding in the future. 


\section{Classical and modern breeding}

Multiplication in vivo and in vitro

Nearly all ornamental cut flowers in the Dutch top ten most important cut flowers on flower auction are propagated vegetatively; these include roses, chrysanthemums, carnations, tulips, gerberas, freesias, Alstroemeria, and lilies, but exclude sunflowers and golden rods. For garden plants, most plants are multiplied by seed, especially F1 hybrid seeds for petunias, pelargoniums, and violas. For in-door plants, both seed multiplication and vegetative propagation are done: primula and cyclamen are normally seed propagated, whereas hedera, kalanchoe, ficus, and pot chrysanthemum are vegetatively multiplied.

The breeder wants to control his or her plant materials. In the case of vegetative propagation, only growers can order the plant materials, and they have to pay licenses to the breeder. Breeders and growers keep in close contact, and the breeder visits the growers regularly to give advice about the growth and culture conditions. As such, the grower can also be controlled if he or she has multiplied the plants for his own use. In most countries in the world, the breeder's rights are justified so that multiplication is illegal, The grower (such as so-called hobby breeders) may use the plants for a crossing program, but the results must be shared with the breeding companies, and these companies will often offer a price for the best plant materials. In most cases, the hobby breeder will sell his or her material to the breeding company.

In the case of seed production, the breeder will protect his or her parental gene pool through the production of hybrid varieties. In this case, he or she will produce parental inbred lines that can be crossed for the production of hybrid seeds to protect plant materials for further production because the grower can never reproduce the same F1 seeds if he or she does not have the same parental inbred lines.

The vegetative propagation of cut flower plants are done on a large scale by specialized companies. Roses are multiplied by grafting or ovulating Rosa canina rootstocks, which are multiplied by special companies. Carnations and Dendranthema are multiplied by cuttings from selected and disease-free "mother plants" mostly grown in greenhouses in countries with a warmer climate, like the south of Italy. Weekly cuttings are transferred to greenhouses in the Netherlands where they are rooted (using special hormones) under a high humidity, and after rooting, the young plants are transported to the growers. Logistics is very important to raise the exact number of plants and to transfer them on time. Robots that transfer the young plants in the greenhouses over long distances are all automatically programmed by computers. Alstroemeria multiplication was done by splitting the rhizomes of in vivo-grown plants, thus resulting in four to six plants per year. Mass propagation via rhizome culture was developed in the breeding line of Alstroemeria (Park et al. 2017). Also, regeneration system with a high efficiency in Alstroemeria plants developed by using both the leaves with axil tissues (Lin et al. 1997) and FEC (friable embryogenic callii) clumps (Kim et al. 2006) Recently, all Alstroemeria breeding companies have applied a system for in vitro multiplication of rhizomes to enable them to produce not only more plants per year (multiplication rate is generally low at 2.0 per month) but also virus-free plants. This is preferable because various viruses of which alstroemeria mosaic virus (AlMV) is the most dreadful may infect Alstroemeria. AlMV is easily mechanically spread and by aphids, and most cultivars do not show clear symptoms when infected by AlMV. However, infection by the virus may lead to a lower quality in the flowers and a lower yield (Van Zaayen 1995).

The multiplication of tulip and lily bulbs is done on a large scale in production fields, although small-scale in vitro multiplication is possible (but is too expensive). Gerbera multiplication is done by seed for pot plant gerbera whereas cut flowers are multiplied in vitro by adventitious shoot formation. Special cultivars are mass propagated in vitro in countries with lower labor costs. Each year, a new start of the in vitro culture of a special cultivar should be repeated because through in vitro multiplication, somaclonal variations could be enhanced. To be sure that the young plants are of the same quality and genotype as the "mother plant," the explants should be refreshed at least once a year. Control of the grown plants is always needed.

\section{Mutation breeding}

For mutation breeding and transformation, a reliable regeneration system is a prerequisite. Both systems should be developed for a small change in the genotype of a plant whereas most of the phenotypic traits should be maintained. Mutation breeding is still the most common breeding technique for ornamentals through which gamma or X-ray radiation can lead to small deletions in the genetic constitution of ornamentals, which can then lead to other colors in a good phenotypic background.

Mutation breeding is a non-directive method, and the results are not predictable. In most cases, mutations lead to death; sometimes they lead to chimeric structures when only the epidermal cell layer has changed. To apply mutagenic agents, plant regeneration is needed, especially a 
system in which the organs originate from one cell. In such a system, no chimeras will appear after the mutagenetic treatment of one cell.

In Dendranthema, mutation breeding is still a standard procedure, especially when a promising cultivar is produced. Spontaneous mutants are well known in chrysanthemum, especially the color mutants; a sector of the flower will another color (mostly corolla florets and/or disk-florets). Using these florets together with flower stems, axillary buds and small leaves for explanting in a regeneration system lead to the development of complete color mutants. Thus a "family" of mutants can be produced from one original cultivar. Breeding companies will induce the mutations artificially in promising cultivars to keep their cultivars and derived breeding material within their own company. Recently, new cultivars in roses have been produced by in vitro mutagenesis. Mutation breeding in combination with in vitro techniques through the use of adventitious bud formation could increase the variability for qualitative traits in roses. The availability of in vitro micropropagation techniques has facilitated the induction of mutations and the selection of mutants of interest. Different flower colors and flower shape mutants were selected in roses through this system. To remove the chimeric structure of several mutants, a cyclic regeneration based on adventitious bud formation on leaflet explants was successfully applied (Ibrahim 1999). Also, gamma-ray was applied for production of mutation for new colors in flower from rooted cutting of Coreopsis roses Nutt (Park et al. 2014).

\section{Gene transformation}

Genetic transformation seems to be a good tool for breeding ornamentals due to the small changes needed in ornamentals to gain good results, like changes in colors, shape, etc. For instance, if the biochemical pathway to produce color pigments is disturbed by the introduction of genes, new colors can easily be induced without changes in the plant and flower architecture. Other genes can improve the vase life of flowers or the size and architecture of the plant, and the flowers that result from each change has potential value in ornamentals (Mol et al. 1995). Another reason for the production of transgenic ornamentals is the idea that transgenic ornamentals could be easily accepted by consumers. Through transgenic ornamentals, the acceptance of transgenic food could presumably be easier. At least, this was the case before the introduction of the transgenic soya in Europe. In the dicotyledonous ornamentals, roses, carnations,
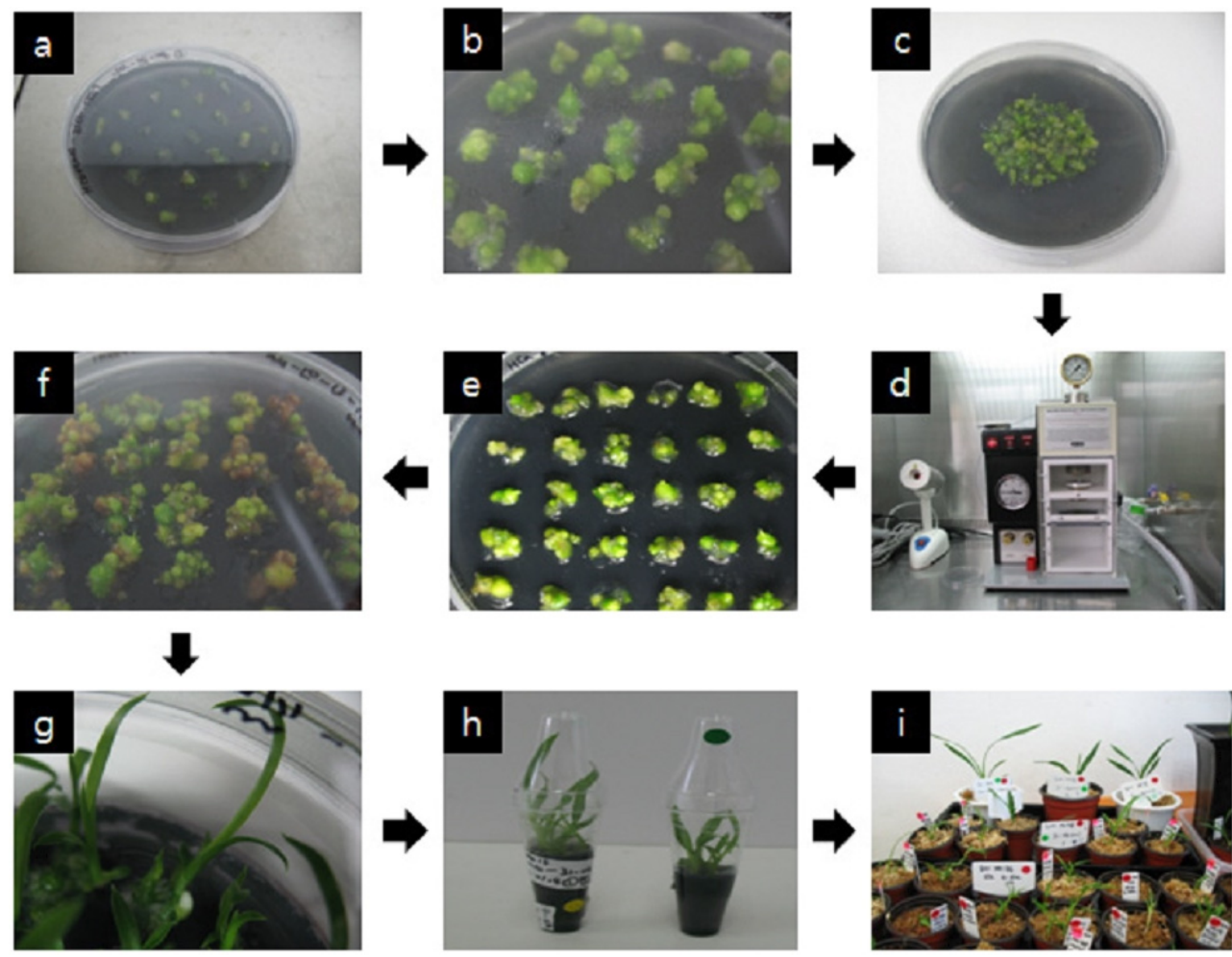

Fig. 1 Transformation of Cymbidium plants by particle bombardment (Source: Roh et al. 2011)

a: Initial growth of PLB (protocorm-like bodies), b: Propagation of PLB with shoots c: Pre-culture of Cymbidium PLBs for 2 days, $\mathrm{d}$ : Bombarding using particle bombardment, e: Delayed selection time for 3 weeks, f: Transfer to HCa medium with PPT 5 mg/l, g: Regeneration of putative transgenic plants, h: Growing of putative transgenic plants, i: Acclimatization of transgenic cymbidium plants 
chrysanthemums, and gerbera transformation systems with Agrobactrium tumefaciens as the vector are applied routinely nowadays. For the monocotyledonous ornamentals tulips, lilies, and Alstroemeria, transgenic plants have recently been developed, although research is still needed.

\section{Gene transfer in monocotyledonous ornamentals}

Detailed information on the development of transformation system for monocotyledonous ornamentals will be provided. Although many transformation protocols have been published for dicotyledonous ornamentals in the past few years, protocols for monocotyledonous ornamentals are rather poor. If the monocot is a host for Agrobacterium tumefaciens as it happened to be in Anthurium (Chen \& Kuehnle 1996) and in Lilium (Langeveld et al. 1995), positive results are expected in normal regeneration systems. Kim et al (2007) optimized several factors such as co-cultivation period, infection time, dilution factor and the concentration of acetosyringone to generate transgenic plants using Agrobacterium tumafaciens in Alstroemeria.

Chen and Kuehnle (1996) produced stable transformants in Anthurium. Langeveld et al. (1995) demonstrated transient expression in stem internodes. For the application of the particle gun as a gene delivery system, several attempts were made for differentiated tissues. Wilmink (1996) applied particle bombardment to the floral stem segments in Tulipa. The transgenic tulip plants regenerated from these segments were chimeric. In Dendrobium, protocorms were particle bombarded, and afterward, selection with kanamycin as the selection agent for transgenic orchids were obtained (Kuehnle \& Sugii 1992). In orchid plants, PLBs (protocormlike bodies) were used for particle gun-mediated transformation in Cymbidium (Roh et al. 2011, shown in Fig. 1) and Phalaenopsis (Roh et al. 2012, shown in Fig. 2) as an explant which showed high transformation efficiencies. Although there were some successful results found in differentiated tissue, more results were obtained after the particle bombardment of a good regenerating callus. As initial explants for the induction of regenerable callus in monocots, different plant organs were used, such as the (im)mature embryo in Alstroemeria (Hutchinson et al. 1994, 1997; Van Schaik et al. 1996; Van Schaik 1998), the seeds in Asparagus (Cabrera-Ponce et al. 1997), the corm in Gladiolus (Kamo et al. 1995), the bulblet scale in Lilium (Watad et al. 1998; Kim 2017, shown in Fig. 3). As a result, an embryogenic cell suspension culture or friable embryogenic callus (FEC) was formed in which particle bombardment applied in Alstroemeria (Lin et al. 2000; Kim 2020a, shown in Fig. 4).
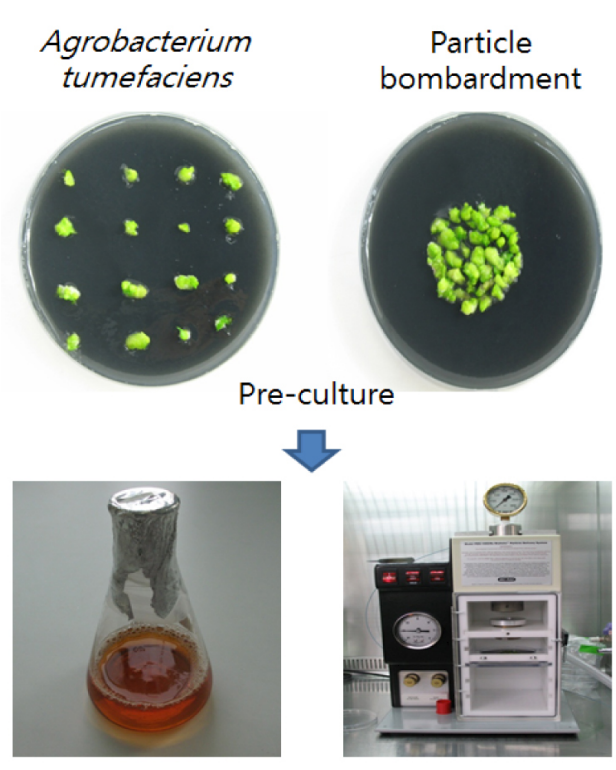

DNA transferred to Phalaenopsis PLBs

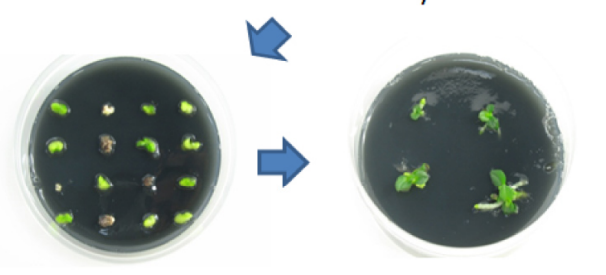
$\begin{array}{cc}\text { PLB selection } & \text { Regeneration of putative } \\ (5 \mathrm{mg} / \mathrm{l} \mathrm{PPT}) & \text { transgenic plantlets }\end{array}$

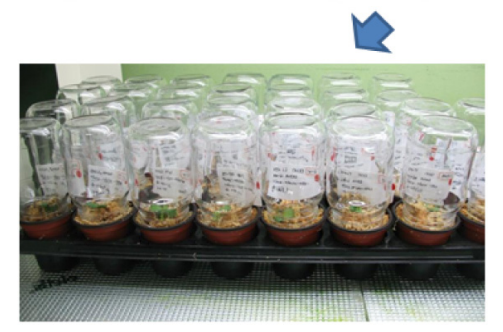

Acclimatization of Transgenic plants
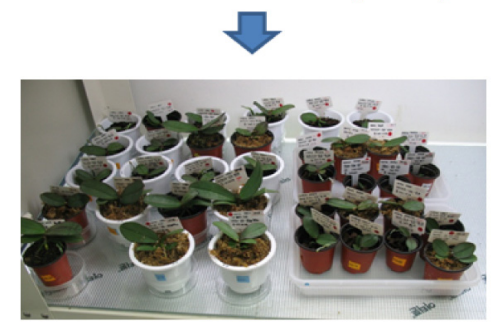

Transgenic Phalaenopsis plants established in pot

Fig. 2 Transformation of Phelaenopsis plants by particle bombardment (Source: Roh et al. 2012)

Further, FEC cultures were used for the production of transgenic virus-resistant Alstroemeria plants via particle bombardment (Kim 2020b). In Asparagus and Gladiolus, these transformation experiments were successful and resulted in stable transgenic plants (Cabrera-Ponce et al. 1997, Kamo 


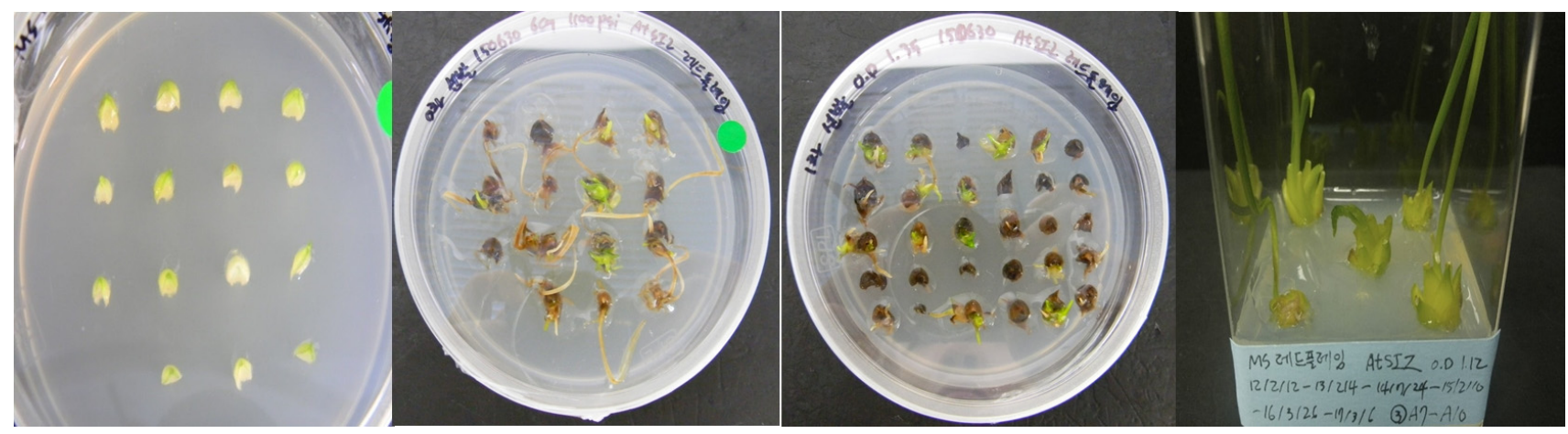

Fig. 3 Transformation of lily plants by particle bombardment (Source: Kim 2017)
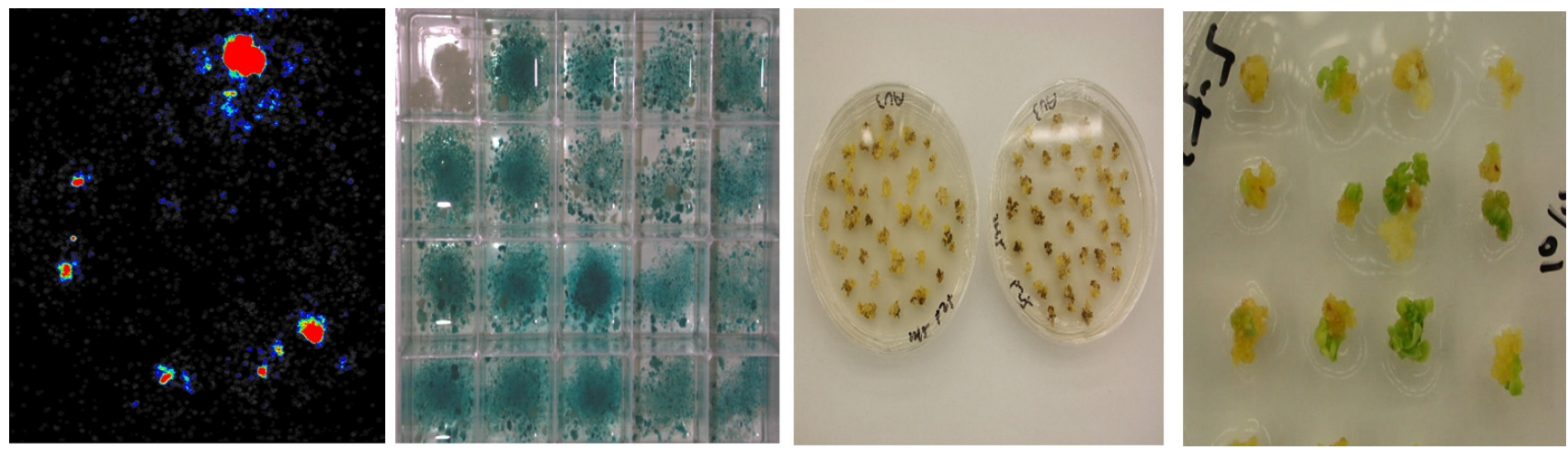

Fig. 4 Transformation of Alstroemeria plants by particle bombardment (Source: Kim 2020a)

et al. 1995). The most suitable regeneration system should consist of small embryogenic callus clusters that multiply fast and do not lose their regeneration ability. It is expected that particle bombardment of this type of callus will generate transgenic embryogenic calli, which will regenerate into stable transgenic plants after the use of selection markers (Raemakers et al 1997; Lin 1998; Kim 2010a and 2020b).

\section{Molecular techniques for ornamental breeding}

For genotype identification and for the determination of genetic variation molecular DNA techniques are available in ornamentals varying from isozyme analysis, RFLP to PCR-based techniques like RAPD and AFLP. Isozyme analysis can be done on leaf extracts whereas all the other techniques are based on DNA isolation. Laboratory equipment is needed for the application of these techniques. Some examples of molecular techniques for the determination of the genetic variation in a collection are characterization of Hydrangea collection using isoenzyme analysis of nuclear DNA contents in Hydrangea (Lambert et al. 1998), RAPD analysis of natural diversity in genus Rosa (Reynders-Aloisi et al. 1995) and AFLP analysis in Alstroemeria (Han et al., 2002). Genotype identification can be done by several tech- niques including RAPD analysis for genotype identification in Alstroemeria (De Benedetti et al. 1998), use of speciesspecific probes in Alstroemeria (De Jeu et al. 1995), molecular cytogenetics with FISH and GISH in Alstroemeria (Kamstra et al. 1997, Kuipers et al 1997).

\section{Breeding techniques in the future}

Modification of horticultural traits via CRISPR/Cas9 system

New tools for ornamental breeding have deviated from the use of transgenes and molecular techniques for the identification of plant material and for marker-assisted breeding. In addition, the need for the selection of insect- and diseaseresistant ornamentals will be a topic for the future when the use of pesticides will be forbidden or at least restricted. In principle, the companies involved in ornamental breeding will maintain the classical way of breeding whereas these modern tools will be applied to classical breeding programs.

Recently, new technique of CRISPR/Cas9 (Clustered Regularly Interspaced Short Palindromic Repeats/CRISPR associated 9) has been applied for breeding systems for crop improvement due to its simplicity and high efficiency (Karkute et al. 
Table 1 List of modification of traits via the CRISR/Cas 9 technology in ornamentals

\begin{tabular}{|c|c|c|c|c|}
\hline Species & Target gene(s) & Target traits & Method & References \\
\hline $\begin{array}{l}\text { Chrysanthemum } \\
\text { moriforium }\end{array}$ & $\begin{array}{c}\text { Yellow-green } \\
\text { fluorescent }(C p Y G F P)\end{array}$ & $\begin{array}{l}\text { Fliorescent protein } \\
\text { disruption }\end{array}$ & Agrobacterium & Kishi-Kaboshi et al. (2017) \\
\hline Lilium longifolium & $L p P D S$ & Albino phenotype & Agrobacterium & Yan et al. (2019) \\
\hline Petunia & $\begin{array}{c}\text { Phytoene desaturase } \\
\text { (PhPDS) }\end{array}$ & Albino phenotype & Agrobacterium & Zhang et al. (2016) \\
\hline Petunia & $\begin{array}{l}\text { Nitrate reductase } \\
\qquad(\mathrm{PhNR})\end{array}$ & $\begin{array}{l}\text { Defficiency in nitrate } \\
\text { assimilation }\end{array}$ & PEG-mediated & Subburaj (2016) \\
\hline Phalaenopsis & MADS & $\begin{array}{c}\text { Floral initiation and } \\
\text { development }\end{array}$ & Agrobacterium & Tong et al. (2019) \\
\hline Torenia fournieri & $\begin{array}{c}\text { Flavanone 3-hydroxylase } \\
\text { gene }(\mathrm{F} 3 \mathrm{H})\end{array}$ & Flavonoid biosysthesis & Agrobacterium & Nishihara et al. (2018) \\
\hline
\end{tabular}

2017). Therefore, this technique is widely employed and improved for traits in a lots of crops (Karkute et al. 2017). Until now, GM techniques including electroporation, PEGmediated transformation, particle bombardment and Agrobacterium tumefaciens have been used for the production of transgenic crops which have manly either herbicideresistance or insect-resistance in many crops such as corn, cotton and soybeans. However, transgenic crops derived from GM techniques have serious concern for commercialization and side-effect for ecosystem. In the last 10 years, however, CRISPR/Cas9 technique was proved an efficient tool for breeding and used for alteration of the target site of the genome in many horticultural crops in fruits and vegetables (Karkute et al. 2017). However, it also has been used in ornamental crops (Table 1).

In ornamental crops, CRISPR/Cas9 system can be used for the modifications of colors in flower, productions of fragrance, alterations of size and extending of shelf-life on vase. In addition, abiotic and biotic stress resistances can be enhanced and useful for many crops (Corte et al. 2019). For example, CRISPR/Cas9 was used to show pale blue flowers with a high efficiency (c.a. $80 \%$ from the regenerated lines, Nishihara et al. 2018). The production of transgene-free ornamental plants using CRISPRCas9 is important under the current regulations and cost for GM plants. However, although CRISPR/Cas9 has many advantages over conventional GM techniques at this time, it still needs regeneration system from protoplast cells and optimized transformation system to operate CRISPR/Cas9 system well. Further, we have some concerns on the effects of mutations on non-target genes in plants which have large and complex genomes when CRISPR/Cas9 is applied (Corte et al. 2019). In the near future, when improvements on regeneration process and transformation system as well as the modification for CRISPR/Cas9 technology are successfully completed, this new breeding technique can be widely applied for many ornamental plants to change traits and satisfy demand for consumers.

\section{General conclusion}

Flower breeding started as hobby breeding, and now, it has developed into a scientific research program in which a lot of money has been invested. However, classical way of breeding using genetic variations supplied by nature is still very important and will remain so in future. Only in special occasions will the use of transgenes be required because the costs are very high, and its general acceptance by consumers is still very low. The development of molecular tools for identification, genetic transformation and genomeediting techniques are very useful and will become indispensable in future.

\section{References}

Bayer E (1987) Die Gattung Alstroemeria in Chile. Mitt. Bot. Staatssamml. München 24:1-362

Buitendijk JH, Pinsonneaux N, Van Donk AC, Ramanna MS, and Van Lammeren AAM (1995) Embryo rescue by half-ovule culture for the production of interspecific hybrids in Alstroemeria. Sci. Horti. 64:65-75

Busmann-Loock A, Dambroth M and Menge-Hartmann U (1992) Histological observations on interspecific crosses in the genus Lupinus. Plant Breed 109:82-85

CabreraPonce JL, Lopez L, AssadGarcia N, MedinaArevalo C, Bailey AM and HerreraEstrella L (1997) An efficient particle bombardment system for the genetic transformation of asparagus (Asparagus officinalis L.). Plant Cell Rep 16:255260

Chen FC and Kuehnle AR (1996) Obtaining transgenic Anthurium through Agrobacterium-mediated transformation of etiolated internodes. J Amer Soc Hort. Sci 121(1):47-51 
Corte LED, Mahmoud LM, Moraes TS, Mou Z, Grosser JW, Dutt M (2019) Development of improved fruit, vegetable, and ornamental crops using the CRISPR/Cas9 genome editing technique. Plants 8:601

De Benedetti L, Burchi G, Mercuri A, Schiva T (1998) Use of RAPD analysis for genotype identification in Alstroemeria interspecific hybrids. Abstracts EUCARPIA $19^{\text {th }}$ Intern. Symposium-Improvement of ornamental plants, Angers, France

De Jeu MJ and Jacobsen E (1995) Early postfertilization ovule culture in Alstroemeria L. and barriers to interspecific hybridization. Euphytica 86:15-23

De Jeu MJ, Lasschuit J, Chevalier F, Visser RGF (1995) Hybrid detection in Alstroemeria by use of species-specific repetitive probes. Acta Hort 420:62-64

De Jeu MJ and Garriga Calderé F (1997) Retarded embryo growth and early degeneration of sporophytic tissue are associated with embryo abortion in the interspecific cross Alstroemeria pelegrina x Alstroemeria aurea. Can J Bot 75:916-924

De Wit JC, Esendam HF, Stracers LJM, Aapola A, Elomaa P, Honkanen J, Ljungberg H, Seppänen P, and Törmälä T (1990) Production of haploid Gerbera clones through ovule culture. Poster Symposium EUCARPIA Section Ornamentals 10-14 November 1990, Wageningen, The Netherlands

Forkmann G, Dedio J, Henkel J, Min BW, Wassenegger M (1995) Genetics, biosynthesis and molecular biology of flower colour of Dianthus caryophyllus (carnation) Acta Hort 420: 29-31

Han DS, Niimi Y and Nakano M (1997) Regeneration of haploid plants from anther cultures of the Asiatic hybrid lily 'Connecticut King'. Plant Cell Tiss Organ Cult 47(2):153-158

Han TH, Van Eck H, De Jeu MJ, Jacobsen E (2002) The construction of a linkage map of Alstroemeria aurea by AFLP markers. Euphytica 128:153-164

Honda K and Tsutsui K (1997) Production of interspecific hybrids in the genus Delphinium via ovule culture. Euphytica 96: 331-337

Hutchinson MJ, Tsujita JM and Saxena PK (1994) Callus induction and plant regeneration from mature zygotic embryos of a tetraploid Alstroemeria (A. pelegrina x A. psittacina). Plant Cell Rep. 14: 184-187

Hutchinson MJ, Senaratna T, Tsujita JM and Saxena PK (1997) Somatic embryogenesis in liquid cultures of a tetraploid Alstroemeria. Plant Cell Tiss Organ Cult. 47: 293-297

Ibrahim R (1999) In vitro mutagenesis in roses. Ph. D thesis University of Ghent, Belgium

Ishizaka H and Uematsu J (1992) Production of interspecific hybrids of Cyclamen persicum Mill. and C. hederifolium Aiton. by ovule culture. Jap J Breeding 42:353-366

Janson J, Reinders MC, Van Tuyl JM and Keijzer CJ (1993) Pollen tube growth in Lilium longiflorum following different pollination techniques and flower manipulations. Acta Bot. Neerl. 42:461-472

Kamo K, Blowers A, Smith F, Van Eck J and Lawson R (1995) Stable transformation of Gladiolus using suspension cells and callus. J Amer Soc Hort Sci. 120:347-352.
Kamstra SA, Kuipers AGJ, De Jeu MJ, Ramanna MS, Jacobsen E (1997) Physical localization of repetitive DNA sequences in Alstroemeria: karyotyping of two species with species specific and ribososmal DNA. Genome 40:652-658

Karkute SG, Singh AK, Gupta OP, Singh PM, Singh B (2017) CRISPR/Cas9 mediated genome engineering for improvement of horticultural crops. Front Plant Sci 8:1635

Kim JB, Bergervoet JEM, Raemakers CJJM, Jacobsen E, Visser RGF (2005) Isolation of protoplasts, and culture and regeneration into plants in Alstroemeria. In Vitro Cell Dev Biol Plant 41:505-510

Kim JB, Raemakers CJJM, Jacobsen E, Visser RGF (2006) Efficient somatic embryogenesis in Alstroemeria. Plant Cell Tiss Organ Cult 86:233-238

Kim JB, Raemakers CJJM, Jacobsen E, Visser RGF (2007) Efficient production of transgenic Alstroemeria plants by using Agrobacterium tumefaciens. Ann Appl Biol 151:401-412

Kim JB (2017) Optimization of a protocol for the production of transgenic lily plants via particle bombardment. J Plant Biotechnol 44:82-88

Kim JB (2020a) An efficient protocol for the production of transgenic Alstroemeria plants via particle bombardment. J Plant Biotechnol 47:66-72

Kim JB (2020b) Production of transgenic Alstroemeria plants containing virus resistance genes via particle bombardment. J Plant Biotechnol (in press)

Kishi-Kaboshi M, Aida R, Sasaki K (2017) Generation of gene-edited Chrusanthemum morifolium using multi-copy transgenes as targets and markers. Plant Cell Physiol 58:216-226

Kranz E and Lörz H (1993) In vitro fertilization with isolated, single gametes results in zygotic embryogenesis and fertile maize plants. Plant Cell 5:739-746

Kuehnle AR and Sugii N (1992) Transformation of Dendrobium orchid using particle bombardment of protocorms. Plant Cell Rep. 11:484-488

Kuipers AGJ, Van Os DPM, De Jong JH, Ramanna MS (1997) Molecular cytogenetics of Alstroemeria: identification of parental genomes in interspecific hybrids and characterization of repetitive DNA families in constitutive hetrochromatin. Chrom. Res. 5:31-39

Lambert C, Bertrand H, Lallemand J, Bourguoin M (1998) Characterization of Hydrangea macrophylla collection using isozyme analysis. Abstracts EUCARPIA $19^{\text {th }}$ Intern. SymposiumImprovement of ornamental plants, Angers, France

Langeveld SA, Gerrits MM, Derks AFLM, Boonekamp PM and Bol JF (1995) Transformation of lily by Agrobacterium. Euphytica 85:97-100

Lin HS De Jeu MJ, Jacobsen E (1997) Direct shoot regeneration from excised leaf explants of in vitro grown seedlings of Alstroemeria L. Plant Cell Rep 16:770-774

Lin HS (1998) Development of two in vitro regeneration systems through leaf explant and callus culture and the application for genetic transformation in Alstroemeria. Thesis Wageningen Agricultural University, The Netherlands

Lin HS, Van der Toorn C, Raemakers CJJM, Visser RGF, De Jeu 
MJ and Jacobsen E (2000) Genetic transformation of Alstroemeria using particle bombardment. Mol Breed 6:369-377

Meynet J and Sibi M (1984) Haploid plants from in vitro culture of unfertilized ovules in Gerbera jamesonii. Zeitschrift für Pflanzenzüchtung 93(1):78-85

Mol JNM, Holton TA and Koes RE (1995) Floriculture:genetic engineering of commercial traits. Trends Biotechnol 33:350-355

Murashige T and Skoog F (1962) A revised medium for rapid growth and bioassays with tobacco tissue culture. Physiol Plant. 15:473-497

Nakano M and Mii M (1993) Somatic hybridization between Dianthus chinensis and D. barbatus through protoplast fusion. Theor Appl Genet 86:1-5

Nishihara M, Higuchi A, Watanabe A. Tasaki K(2018) Applications of the CRISPR/Cas9 system for modification of flower color in Torenia fournieri. BMC Plant Biol 18:331

Park KY, Hwang HJ, Chae WB, Choi GW (2014) Development of a new variety 'Uridream Pink' by gamma-ray irradiation. Kor J Hort Sci Technol 32(6): 906-911

Park SW, Lee SH, Kim JB, Jung HJ, Wi SG, Han TH (2017) Development of mass propagation system via rhizome culture in elite breeding line C269 of Alstroemeria. Flower Res J 25(4): 232-239

Raemakers CJJM, Sofiari E, Jacobsen, Visser RGF (1997) Regeneration and transformation of cassava. Euphytica 96: 153-161

Ramanna MS (1992) The role of sexual polyploidization in the origins of horticultural crops: Alstroemeria as an example. In: Mariani A., Tavoletti S. (eds.): Proceedings of the workshop: Gametes with somatic chromosome number in the evolution and breeding of polyploid polysomic species: Achievements and perspectives, Perugia, Italy: 91-99

Reiser W and Ziessler CM (1989) Die Uberwindung postgamer Inkompatibilität bei Freesia-Hybriden. Tag,-Ber., Akad. Landwirtsch.-Wiss. DDR, Berlin 281:135-138

Reynders-Aloisi S and Bollereau P (1995) Characterization of genetic diversity in the genus Rosa by random amplified polymorphic DNA. Acta Hort 424:253-260

Roh HS, Kim MS, Lee YM, Lee YR, Lee SI, Kim JB (2011) Optimization of particle gun-mediated transformation system in Cymbidium. J Plant Biotechnol 38:293-300

Roh HS, Lee SI, Lee YR, Baek SY, Kim JB (2012) Recent trends in tissue culture and genetic transformation of Phalaenopsis. $\mathrm{J}$ Plant Biotechnol 39:225-234

Subburaj S, Chung SJ, Lee C, Ryu SM, Kim DH, Kim JS, Bae S, Lee GJ (2016) Site-directed mutagenesis in Petunia X hybrid protoplast system using direct delivery of purified recombinant Cas9 ribonucleoproteins. Plant Cell Rep 35:1535-1544

Tian HQ and Russell SD (1997) Micromanipulation of male and female gametes of Nicotiana tabacum: II Preliminary attempts for in vitro fertilization and egg cell culture. Plant Cell Rep 16: 657-661

Tong CG, Wu FH, Yuan YH, Chen YR, Lin CS (2019) Highefficiency CRISPR/Cas-based editing of Phalaenopsis orchids MADS genes. Plant Biotechnol J 18(4):889-891
Van den Bulk RW, de Vries-van Hulten HPJ, Custers JB and Dons JJM (1994) Induction of embryogenesis in isolated microspores of tulip. Plant Sci 104:101-111

Van Creij MGM (1997) Interspecific hybridization in the genus Tulipa L. Thesis Wageningen Agricultural University, The Netherlands 163 pp

Van Schaik CE, Posthuma A, De Jeu MJ and Jacobsen E (1996) Plant regeneration through somatic embryogenesis from callus induced on immature embryos of Alstroemeria spp. L. Plant Cell Rep 15:377-380

Van Schaik CE (1998) Regeneration and transformation of Alstroemeria. Thesis Wageningen Agricultural University, The Netherlands $111 \mathrm{pp}$

Van Tuyl JM, Van Diën MP, Van Creij MGM, Van Kleinwee TCM, Franken J and Bino RJ (1991) Application of in vitro pollination, ovary culture, ovule culture and embryo rescue for overcoming incongruity barriers in interspecific Lilium crosses. Plant Sci 74:115-126

Van Tuyl JM, Meijer H, Van Diën MP (1992) The use of oryzalin as an alternative for colchicine in vitro chromosome doubling of Lilium and Nerine. Acta Hort 325:625-630

Van Tuyl JM, Van Creij MGM, Eikelboom W, Kerckhoffs DMFJ and Meijer B (1993) New genetic variation in the Lilium and Tulipa assortment by wide hybridization. In: Proceedings of the XVIIth Eucarpia Symposium (Eds. T. Schiva and A. Mercuri), Sanremo, Italy pp 141-149

Van Tuyl JM and De Jeu MJ (1997) Methods for overcoming interspecific crossing barriers. In: Pollenbiotechnology for Crop Production and Improvement (Eds. V.K. Sawhney and K.R. Shivanna) Cambridge University press, New York pp 273-292

Van Zaayen A (1995) Alstroemeria In: Virus and virus-like diseases of bulb and flower crops. Eds. G. Loebenstein, RH Lawson, AA Brunt, Whiley \& Sons, UK pp 237-249

Vazquez-Thello A, Yang LJ, Hidaka M and Uozumi T (1996) Inherited chilling tolerance in somatic hybrids of transgenic Hibiscus rosa-sinensis x transgenic Lavatera thuringiaca selected by double-antibiotic resistance. Plant Cell Rep 15:506-511

Watad AA, Yun DY, Matsumoto T, Niu X, Wu Y, Kononowicz AK, Bressan RA and Hasegawa PM (1998) Microprojectile bombardment-mediated transformation of Lilium longiflorum. Plant Cell Rep. 17:262-267

Wilmink A (1996) Genetic modification of tulip by means of particle bombardment. Thesis University of Nijmegen, The Netherlands

Yan R, Wang Z, Ren Y, Li H, Liu N, Sun H (2019) Establishment of efficient genetic transformation systems and applications of CRISPR/Cas9 genome editing technology in Lilium pumilium DC. Fisch. and Lilium longifolium White Heaven. Int J Mol Sci 20:2920

Zhang B, Yang X, Yang C, Li M, Guo Y (2016) Exploiting the CRISPR/Cas9 system for targeted genome mutagenesis in Petunia. Sci Rep 6:20315 